\title{
Carbon credits for cookstoves: tradeoffs in climate and health benefits
}

Olivia E. Freeman ${ }^{1}$ and Hisham Zerriffi ${ }^{2}$

The authoritative published version may be found at: http://pubs.cif-ifc.org/journal/tfc

${ }^{1}$ Institute of Resources, Environment and Sustainability, University of British Columbia, 2202 Main

Mall, Vancouver, BC V6T 1 Z4 Canada. Corresponding author: Freeman, Olivia E.

(olivia.e.freeman@gmail.com)

${ }^{2}$ Liu Institute Global Issues, University of British Columbia, 6476 NW Marine Dr., Vancouver, BC V6T 1 Z2 Canada. 


\begin{abstract}
Cookstove projects have long been considered 'win-win' development projects based on the multitude of benefits they can create. Carbon credits provide a new financing mechanism to fund such cookstove projects, but have been critiqued as not always successfully meeting sustainable development goals. By drawing on previous literature this article critically looks at tradeoffs between the maximization climate and health benefits of cookstove projects in the context of carbon credits. It finds that carbon credits inherently account for climate benefits, but not for health. Therefore clear objectives of cookstove interventions need to be defined prior to project implementation to insure the maximization of benefits in projects' priority areas.
\end{abstract}

Key words: Cookstove, carbon credit, sustainable development, indoor air pollution, win-win benefits, greenhouse gases, black carbon, Clean Development Mechanism, Gold Standard

\title{
Introduction
}

Nearly half of the wood harvested globally is used as fuelwood (FAO 2002). More than 3 billion people, almost all of which are in developing countries, rely on some form of solid biomass to meet their cooking and heating needs (Legros et al. 2009). A large percentage of these households still rely on some form of traditional stove to meet these needs, as only 828 million people worldwide use an 'improved' cookstove on a daily basis, two, thirds of which live in China (Legros et al. 2009). An 'improved' cooking technology is a term that is used liberally. ${ }^{3}$ It usually refers to a stove with

\footnotetext{
${ }^{3}$ See Smith and Dutta (2011) for discussion about the appropriateness of the word 'improved' to describe cleaner cooking technologies.
} 
increased efficiency, more complete combustion, and better heat transfer. ${ }^{4}$ This corresponds to a decrease in fuel use, and decreased emission of smoke and particles emitted through incomplete combustion. As a result, switching from a traditional ${ }^{5}$ or less efficient cooking technology to an improved cooking technology has long been considered a 'win-win' development project due to the co-benefits that can result (Barnes et al. 1993, Smith and Haigler 2008, Simon et al. 2012). The benefits of transitioning to this technology can include all three major components of sustainable development, social, environmental and economic benefits:

- Social benefits (Mostly impacting women and children): reduction of indoor air pollution (IAP) (Bruce et al. 2000, Smith et al. 2000a, Smith and Mehta 2003, Rehfuess 2006), reduced physical burden and risk associated fuelwood collection (Patrick 2007, Wickramasinghe 2003, Matinga 2008), empowerment of women (Rehfuess 2006, Parikh 2011)

- Environmental benefits: decreased pressure on fuel resources (e.g. woody biomass) (Barnes et al. 1993, Rehfuess 2006), reduction of climate forcers (e.g. greenhouse gases (GHGs)) emitted (Bond et al. 2004, Smith and Haigler 2008, Greishop et al. 2011)

- Economic benefits (See Barnes et al. 1993, Hutton et al. 2006, and Rehfuess 2006): reduced expenditures (if paying for fuel), time savings, increased productivity, decreased health costs, potential engagement in other economic generating activities, job creation

\footnotetext{
4 Some literature distinguishes between 'improved' cookstoves that continue to burn solid fuels, only more efficiently and cleanly, and 'modern' fuels and technologies, such as electric stoves or liquefied petroleum gas (LPG) stoves that avoid using solid fuels in the household entirely. 5 Traditional cookstoves include 'three-stone' fires and hand built mud stoves. Both are characterized by inefficiency and generation of smoke.
} 
However, significant barriers remain for diffusing both improved solid fuel stoves and more modern fuels and technologies for cooking, including major cost impediments for the primarily poor and rural populations using traditional stoves.

Though people have been improving and experimenting with cooking technologies for centuries, global interest in investing in such programs through non-governmental organizations (NGOs) and governmental channels first occurred in the 1970's (Barnes et al. 1993). This was born out of the concern about world energy supply and perceived rates of deforestation (Barnes et al. 1993, Top et al. 2004, Elias and Victor 2005). Hundreds of improved cookstove projects have been implemented since then with the rationale for implementing such cookstove projects shifting from focusing on relieving pressure on biomass resources to the combination of development and environmental benefits that can be generated (e.g. Bailis et al. 2005, Elias and Victor 2005, Hutton et al. 2006, Smith and Haigler 2008, Simon et al. 2012).

There also now exists extensive literature about various aspects of cookstoves including: estimation of both development and environmental benefits (e.g. Mehta and Shahpar 2004, Hutton et al. 2006, Smith and Haigler 2008), scientific analysis of aerosol emissions (e.g. Zhang et al. 2000, Roden et al. 2006, Jetter and Kariher 2009), impacts on health (e.g. Bruce et al. 2000, Smith et al. 2000a, Smith et al. 2009b), critical analysis of project implementation (e.g. Smith et al. 1993, Hanbar and Karve 2002, Sinton et al. 2004, Bumpus 2009, Troncoso et al. 2011), analysis of diffusion business models (e.g. Shrimali et al. 2011, Zerriffi 2011, Chaurey et al. 2012), and factors influencing adoption of new technologies (e.g. Bailis et al. 2009, Pine et al. 2011, Ruiz-Mercado et al. 2011, Wickramasignhe et al. 2011). 
The opportunity to earn carbon credits for cookstove projects has generated increased interest in the climate benefits of cookstoves. These carbon credits are especially desirable for carbon credit buyers who are interested in purchasing credits, which promote sustainable development more broadly (Peters-Stanley and Hamilton 2012). Unlike other kinds of carbon credit projects which do not automatically result in sustainable development benefits, cookstove credits are promoted as 'win-win', providing not only reduction of greenhouse gases (GHGs), but also tangible development benefits simultaneously and on an incremental basis (Bumpus 2009, Simon et al. 2012). Yet since the implementation of these projects are relatively new and few have completed a project cycle (Cox 2011), the long-term outcomes are hard to assess (Simon et al. 2012).

A review article by Simon et al. (2012) draws on the limited knowledge and experiences of carbon credit cookstove programs to analyze benefits and barriers in achieving both development and climate benefits through carbon financing for households and communities. Though they acknowledge the unique benefits carbon credits can provide to cookstove projects such as longer project cycles, integrated maintenance, evaluation, monitoring, and a new form of financing, they point out that they can also result in 'mutually supported impediments'. This occurs "when requirements for achieving one set of project objectives directly compromises progress towards another set of objectives." For example the large scale at which cookstove carbon credit projects need to be implemented to be profitable can make the already existing development challenge of providing appropriate uptake of technology on a local, long-term scale an intensified impediment for project successes. Therefore 'win-win' benefits are not simply achieved by implementing a cookstove switch out. Instead project design, implementation, and the potential trade-offs of benefits must be considered. While recognizing that 'win-win' outcomes are not guaranteed in cookstove projects, Simon et al. (2012) only briefly mentions health benefits and do not critically assess tradeoffs between health and climate co-benefits. Instead they assert that health benefits are 
incrementally achieved along with climate benefits, giving cookstoves the prestige of being an inherently 'win-win' carbon credit project in terms of climate and health. Though in many cases health and climate co-benefits are achieved to some level simultaneously, this is not the case for all scenarios and a tradeoff still exists in most cases between the amount of climate and health benefits achieved (Grieshop et al. 2011). Some previous studies have examined this tradeoff in some capacity (e.g. Sinton et al. 2004, Bailis et al. 2005, Grieshop et al. 2011), but none explicitly look at the tradeoffs under the carbon credit framework, which have very specific methodologies for determining climate benefits.

Just as Simon et al. (2012) explores the nuances of 'win-win' between climate and development benefits more broadly, this article examines the tradeoffs between the maximization climate and health benefits of cookstove projects. Health is one major indicator of sustainable development and a key negative consequence of using traditional stoves. Reduced indoor air pollution (IAP) not only contributes to longer lives, but also increases healthy years lived. This can increase quality of life and productivity. Given that climate and health benefits are often assumed to be simultaneously, incrementally achieved, a more nuanced understanding of the relation between the two is needed. This article draws on past studies and literature to examine the tradeoffs between climate and health benefits of cookstove projects under carbon financing schemes. Drawing on the literature this article reviews the definition of health and climate benefits, how cost-effectiveness of cookstove projects impact decisions thereby influencing benefits, and finally synthesizes the reviewed material to examine potential tradeoffs made between the maximization of carbon credits and health benefits. 


\section{Overview: Climate and Health Benefits for Cookstoves}

\section{Products of Incomplete Combustion: Health and Climate Implications}

Incomplete combustion during the use of cookstoves results in the emission of products of incomplete combustion (PICs), which have implications for both climate and health. PICs consist of: inorganic gases (e.g. carbon monoxide (CO), nitrous oxide $\left(\mathrm{N}_{2} \mathrm{O}\right)$ ), hydrocarbons (e.g. non-methane hydrocarbons (NMHC)), oxygenated organics (e.g. organic alcohols), and particulate matter (inhalable $\left(\mathrm{PM}_{10}\right)$, respirable and fine particles $\left(\mathrm{PM}_{2.5}\right)$ ) (Naeher et al. 2007). Nominal combustion efficiencies of cookstoves range from $80-99 \%$ depending on the type of fuel and stove that is being used (Smith et al. 2000b). ${ }^{6}$ The higher the nominal combustion efficiency the less emission of PICs.

The health impacts of the exposure to PICs are commonly quantified by measuring the amount of $\mathrm{PM}_{10}$ or $\mathrm{PM}_{2.5}$, that is, particulates equal to or less than 10 or 2.5 microns in aerodynamic diameter (Sinton et al. 2004, Naeher et al. 2007, Grieshop et al. 2011). The constituents of particulate matter includes components which can be detrimental to health while also having climate implications (Smith et al. 2009a). In particular, organic carbon and sulfates are both climate cooling, while black carbon has significant warming effects (Smith et al. 2009a).

While health benefits are mainly estimated by the reduction of particulate matter emitted, potential climate benefits are determined by the emissions of specific PICs and reduced fuel use. Additionally,

6 This should not be confused with the efficiency of heat transfer or the total energy efficiency of combustion, which can be well below $20 \%$ for traditional stoves. Where nominal combustion efficiency is the amount of chemical energy in the fuel that is released and heat transfer efficiency is the amount of heat or energy released through combustion that is transferred to the cooking pot/absorbed by the food or substance being cooked. 
different cooking fuels have different climate benefits associated with them. For example, charcoal and fossil fuels have upstream production and transportation emissions associated with their use. Charcoal production specifically has high amounts of GHG emissions even though it burns relatively cleanly with minimal emissions of PICs compared to other biomass fuels (Bailis et al. 2005, Grieshop et al. 2011). Biomass, if harvested at a renewable rate can result in zero net emissions of carbon dioxide $\left(\mathrm{CO}_{2}\right)$, though there are additional climate impacts from other climate warming PICs emitted during combustion such as methane $\left(\mathrm{CH}_{4}\right)$ and black carbon. Black carbon has been demonstrated to have very high warming impacts, reduction of which may result in significant climate and health benefits in the case of cookstoves (Grieshop et al. 2009). In general, the cleaner burning the fuel, the higher the combustion efficiency, and the less fuel used for a given cooking task, the less climate forcing and health damaging PICs emitted. This can result in the creation of benefits for both health and climate, but the amount of different benefits varies with each specific technology.

\section{Carbon Credits: How They Work}

Carbon markets were developed as a tool to address global concerns about climate change. The underlying concept of a carbon market is to incentivize the reduction of GHG emissions through the creation of a sellable and tradable unit, the carbon credit, with each credit representing the reduction of 1 ton of $\mathrm{CO}_{2}$ or $\mathrm{CO}_{2}$ equivalent $\left(\mathrm{tCO}_{2} \mathrm{e}\right)^{7}$ emitted. Carbon credits can be created in a number of different ways and contexts. Improved cookstove projects are one of the many projects that can qualify for carbon credits. Their qualification is due to the reduction of GHGs emitted through reduced fuel use and increased combustion efficiencies. Only cookstove projects with some

${ }^{7}$ Additional GHGs beyond $\mathrm{CO}_{2}$, such as $\mathrm{CH}_{4}$, are measured in some cases and converted to tCO $\mathrm{CO}_{2} \mathrm{e}$ units to determine total emissions reductions in one metric. 
percentage of non-renewable fuel usage qualify for carbon credits since the equations for calculating $\mathrm{tCO}_{2} \mathrm{e}$ reduction is based on the amount of non-renewable fuel reduced and emission factors for GHGs included in the respective equations. Woody biomass, some of which is harvested at a non-renewable rate, is the most common fuel used. Therefore areas with high rates of nonrenewable harvesting (or deforestation) will qualify for the most amounts of carbon credits, where areas that are being harvested at a 100\% renewable rate will not qualify at all. Though carbon credit cookstove projects only make up a fraction of global carbon credit programs, these numbers have been rapidly increasing (Blunck et al. 2011).

In the context of cookstove projects, carbon credits provide a means to achieve financial sustainability without requiring end-users to be able to pay the full cost of the stove. They are potentially a significant enabling mechanism to extend the benefits of cookstoves on a much larger scale. In addition to providing much needed financial capital, carbon credits also ensure longer project timelines that have integrated monitoring, evaluation and stove maintenance in order to ensure continued offsets for the life of the project (Simon et al. 2012). This overcomes some of the major limitations of prior stove projects, which suffered from poor follow-up and lacked ongoing support for stove maintenance and replacement. At the same time, significant resources are needed to implement such programs including time, technical expertise and financial capital to pay for the certification process, all of which can act as barriers.

Cookstove projects can be carbon credit certified for both the regulated compliance market to meet Kyoto Protocol targets (e.g. European Emissions Trading Scheme), or the voluntary market where credits can be bought by individuals, groups or organizations that choose, but are not required to offset emissions (e.g. to offset a personal flight). 
For the compliance market cookstove projects are certified through the Clean Development Mechanism (CDM), which under the Kyoto Protocol mandate includes: “... stimulat[ing] sustainable development and emission reductions..." (UNFCCC 2011). It aims to promote sustainable development by allowing developing countries to sell their carbon offsets to developed countries with commitments to reduce GHG emissions under the Kyoto Protocol. This provides a mechanism for developing countries to make additional income, which can stimulate development through a less carbon intensive path (UN 1998, UNFCCC 2011). The carbon credits within CDM projects undergo external certification and monitoring with detailed methodologies developed for calculating carbon credits for different types of projects. The development benefits of a CDM project do not have the same type of certification process and as long as a project is deemed to contribute to development by the Designated National Authority within the project country, it qualifies for CDM credits. Partially as a result of this difference in approach for carbon credits and development benefits, the CDM has been criticized as not achieving its first goal, sustainable development, and instead being driven mainly by the goal to reduce emissions (For a review of the literature: Olsen 2007, Also see: Cosbey et al. 2005, Figueres 2006, Pearson 2006, Sterk and Wittneben 2006, Bumpus and Cole 2010). Critics argue that using monetary incentives for the implementation of CDM projects can result in the easiest credits being reached first, which may not achieve sustainable development goals (Cosbey et al. 2005, Figueres 2006, Pearson 2006, Sterk and Wittneben 2006, Olsen 2007, Bumpus and Cole 2010).

In contrast, the Gold Standard (GS) is a methodology developed to explicitly address meeting the goal of creating sustainable development alongside emission reductions. GS certification can be used in conjunction with the CDM, generating premium credits for the compliance market, or alone, 
generating credits for the voluntary market (GS 2012). ${ }^{8}$ To ensure higher levels of sustainable development GS requires environmental impact assessments that account for more than just greenhouse gas generation, stakeholder consultations to ensure local participation, and the use of their sustainable development matrix (GS 2011). However, Olsen's (2007) review of the literature does not find the use of sustainability assessment tools, such as GS's sustainability matrix, to effectively offset market forces to ensure sustainable development: "While rhetorically [sustainable development benefits are] mandated in the Kyoto Protocol, they are not monetized and therefore play a limited role in directing investments." She asserts that this does not mean these efforts should be abandoned, but that the inclusion of such tools alone will not necessarily result in sustainable development.

In addition to their different approaches to ensure development benefits, the CDM and GS have different approaches to calculate the amount of carbon credits generated by cookstove projects. Though both have undergone revisions to improve the accuracy in the amount of tCO2e reduction calculated, there still remain uncertainties in both methodologies (Johnson et al. 2010, Bumpus 2011, GACC 2011). In particular, accurate estimates of the fraction of non-renewable biomass are especially challenging to calculate and can have great influence on the number of carbon credits calculated (Johnson et al. 2010, GACC 2011, Simon et al. 2012). Additionally neither equation includes all climate-forcing agents. The $\mathrm{CDM}$ equation only accounts for $\mathrm{CO}_{2}$ reductions whereas the

8 When projects are certified under GS for the voluntary market methodology for calculating carbon credits developed by GS is used. Yet when projects are certified under both CDM and GS, the CDM methodology is used for carbon credit calculations. Under both scenarios the framework of GS, which addresses the sustainable development component is applied. In this paper when the GS methodology is referred to it is referring to credits calculated for the voluntary market. 
GS includes the Kyoto gases that are emitted by cookstoves: $\mathrm{CO}_{2}, \mathrm{CH}_{4}$ and $\mathrm{N}_{2} \mathrm{O}$ (though in cookstove projects $\mathrm{N}_{2} \mathrm{O}$ is usually negligible). Still, both do not account for black carbon, organic carbon, sulfur dioxide $\left(\mathrm{SO}_{2}\right)$, NMHC, or $\mathrm{CO}$ all of which have climate impacts (Grieshop et al. 2011). Therefore carbon credits do not encompass the entirety of climate forcings and potential climate benefits of cookstove projects, but are used as a crude measure of climate benefits is this article's comparison. A critical analysis of calculation specifics of the methodologies and their uncertainties are beyond the scope of this article and the subject of ongoing research.

\section{Measuring Health Benefits}

There are many different kinds of health benefits associated with cookstove projects, mostly impacting women and children (Rehfuess 2006). The most cited health effects of IAP, which also have the strongest scientific support, are chronic obstructive pulmonary disease (COPD), acute lower respiratory infections (ALRI) and lung cancer (Rehfuess 2006). Many studies use these more defendable health measures to evaluate the health implications of different kinds of cookstoves. Including only these three impacts of IAP impacts, the emissions of concentrated smoke from the use of inefficient cookstoves are estimated to cause 1.6 million deaths annually (Rehfuess 2006).

The IAP from solid fuel burning is the result of PICs created through inefficient combustion of fuel. The extent of the health impact will largely be dependent on the intake of particulate matter emitted as part of PICs. Cookstoves with a venting system, such as a chimney, can help to greatly reduce this intake fraction (Mehta and Shahpar 2004, Smith et al. 2009b), but these emissions may still contribute to ambient air pollution, which could still have negative health implications in some scenarios particularly if in a densely populated location (Zhou et al. 2011, Wilkinson et al. 2009). 
Other health impacts related to cookstove use include fatigue and physical strain or injury while cooking and/or collecting fuelwood (Parikh 2011). Additional dangers associated with collection of fuelwood are increased vulnerability to sexual violence for woman and young girls (Patrick 2007), and injury from animals and other natural hazards (Holdren and Smith 2000, Wickramasinghe 2003, Matinga 2008). In this article the measures of health are based upon those that other studies have used, which in most cases are COPD and/or ALRI.

\section{Tradeoffs Between Climate and Health}

A study by Grieshop et al. (2011) shows that health and climate benefits do not have a linear relationship for all cookstove types. Instead, some improved stoves generate higher climate benefits (the reduction of GHGs and other climate-forcing agents) while others generate higher health benefits (in this case relative risk of cardiopulmonary and cardiovascular disease mortality based on emissions of $\mathrm{PM}_{2.5}$ ). ${ }^{9}$ For example, the unvented charcoal stove included in the analysis performed better than most of the biomass stoves in reducing relative health risk, but was one of the top emitters of GHGs ${ }^{10}$. The stoves with the highest 'win-win' benefits, having both low emission of GHGs and $\mathrm{PM}_{2.5}$, were the liquid fossil fuel stoves included in the analysis, the kerosene and liquid petroleum gas (LPG) fueled stoves. Another study by Mehta and Shahpar (2004), also find fossil fuels stoves to have the highest health benefits in comparison with other improved biomass stoves, but note that kerosene creates slightly more IAP than LPG. Additionally they state kerosene has

${ }^{9}$ See Table 1 for stove performances of stoves included in Grieshop et al. (2011)'s study ranked for both health and climate benefits.

10 Due to the large amount of GHGs emissions involved in charcoal production the analysis included charcoal production in the total amount of GHG emissions. 
other health dangers associated with its use, such as poisoning and carcinogenic effects, making LPG the best overall stove for achieving health benefits.

Though Grieshop et al. (2011), provides the most comprehensive demonstration of climate and health tradeoffs in cookstove projects, other studies also have found tradeoffs in other cookstove scenarios. In a review of China's national cookstove program, Sinton et al. (2004) found that although the program was seen as one of the largest successes of cookstove distribution on a large scale, health benefits were not always automatically generated along with the targeted environmental benefits included in the program's objectives. This demonstrates an unintentional tradeoff made between climate and health benefits for a project who's main objective was to reduce pressures on biomass sources. Another study by Bailis et al. (2005) specifically examined climate and health tradeoffs between charcoal and fossil fuel stoves. They found that although both have relatively high health benefits, charcoal stoves have high negative climate impacts from the emission of GHGs both during production and burning of the fuel. Again fossil fuel stoves performed the best for both climate and health outcomes. 
Table 1: Different stoves ranked based on their health and climate performance from Grieshop et al. (2011). Climate benefits have two categories, 'Kyoto Gases' which only includes $\mathrm{CO}_{2}$ and $\mathrm{CH}_{4}$ and 'Total GWP' which includes $\mathrm{CO}_{2}, \mathrm{CH}_{4}, \mathrm{CO}_{\text {, }}$ NMHC, $\mathrm{OC}, \mathrm{BC}$, and $\mathrm{SO}_{2}$. Health benefits are estimated and ranked by an individual intake fraction in mg $\mathrm{PM}_{2.5}$ per day. Stoves are ranked from the least amount of emissions or intake at the top to the most emissions or intake at the bottom for climate and health categories.

The stoves included in their analysis: $\mathbf{W}-\mathbf{T r}-\mathbf{U}=$ traditional unvented wood stove; $\mathbf{W}-\mathbf{I m}-\mathbf{U}=$ improved, Indian, unvented, metal, wood stove; W-Im-V = improved, Chinese, unvented, brick, wood stove; W-Pat-V = improved, Mexican, 'Patsari', vented, mason, wood stove; W-Gas-U = gasifer, Indian, unvented, metal, wood stove; W-Fan-U = 'Philips Fan', unvented, metal, wood stove; Char-U = Indian, unvented, metal/mud, charcoal stove (climate emissions include both use and production); Coal-U = Chinese, unvented, metal, coal stove; Coal-V = Chinese, vented, metal, coal stove; Ker-U = Indian, unvented, metal, kerosene wick stove; LPG-U = Indian, unvented, metal, LPG stove.

\begin{tabular}{|c|c|c|c|}
\hline \multicolumn{2}{|c|}{$\begin{array}{c}\text { Health Benefits } \\
\text { (Individual } \text { PM }_{2.5} \text { Intake Fraction) }\end{array}$} & $\begin{array}{l}\text { Climate Benefits } \\
\text { (Kyoto Gases) }\end{array}$ & $\begin{array}{l}\text { Climate Benefits } \\
\text { (Total GWP) }\end{array}$ \\
\hline \multirow{2}{*}{$\begin{array}{l}<1 \mathrm{mg} / \text { day } \\
\mathrm{PM}_{2.5}\end{array}$} & LPG-U & LPG-U & LPG-U \\
\hline & Ker-U & \multirow{2}{*}{$\begin{array}{l}\text { W-Fan-U/ Ker-U } \\
\text { ( 1mg/day) }\end{array}$} & Ker-U \\
\hline \multirow{6}{*}{$\begin{array}{l}\text { 1-10 mg/day } \\
\mathrm{PM}_{2.5}\end{array}$} & W-Fan-U & & W-Fan-U \\
\hline & Char-U & W-Gas-U & W-Gas-U \\
\hline & W-Pat-V & W-Pat-V & W-Pat-V \\
\hline & Coal-V & W-Im-V & W-Im-U \\
\hline & W-Im-V & W-Im-U & W-Im-V \\
\hline & W-Gas-U & W-Tr-U & Coal-V \\
\hline \multirow{3}{*}{$\begin{array}{l}10-100 \\
\mathrm{mg} / \text { day } \mathrm{PM}_{2.5}\end{array}$} & W-Im-U & Coal-V & W-Tr-U \\
\hline & Coal-U & Coal-U & Coal-U \\
\hline & W-Tr-U & Char-U & Char-U \\
\hline
\end{tabular}

\section{Cost-Effectiveness}

In addition to the benefits that stoves can create and the tradeoffs involved, another major factor influencing the type of stove actually chosen, is their differing cost. This can influence which interventions are possible on what scale and therefore the corresponding benefits included. Cookstoves are viewed in general to be a cost-effective investment to achieve development and climate benefits. There have been both cost-effectiveness analyses and one cost-benefit analysis of such programs all providing strong rational for the investment in cookstoves projects. 
The World Health Organization (WHO) conducted the first cost-benefit analysis of cookstove projects finding them to be a cost-effective intervention based upon the high amount of benefits created when compared to the total costs (Hutton et al. 2006). In their analysis, they compared net cost and benefits of investing in three different intervention scenarios: an improved rocket stove ${ }^{11}$, a biofuel (ethanol) stove and a LPG stove. For costs they included: fuel, stove, and program costs. Economic benefits included measures for: health, productivity gains, time savings from reduced fuel collection and cooking time, and local and global environmental impacts. The analysis was divided into different global locations and each of these was further divided into urban and rural categories. For all scenarios, the benefits outweighed the costs with the majority of the benefits calculated attributable to time savings. In many scenarios, including almost all with the improved rocket stoves, the costs were actually negative due to the high amount of benefits generated. Though there had been previous cost-effective analyses for cookstoves, this was the first analysis using an economic tool for comparison, the cost-benefit analysis.

Other cost-effective analyses have compared the cost of the various interventions providing similar benefits to determine the most cost-effective intervention. To examine cost-effectiveness of health gains alone of improved cooking technologies, Mehta and Shahpar (2004) compare three scenarios, switching to: a) cleaner fuels (in their case LPG or kerosene), b) an improved stove with a chimney or other form of outdoor venting, or c) a combination of both a and b. In this case, health gains were determined by measures of ALRI and COPD in average annual gain in healthy years. LPG and kerosene had the highest health gains, but were also the most costly. Switching to the improved biomass stoves resulted in a wide variation of health gains, though they were significantly lower

\footnotetext{
${ }^{11} \mathrm{~A}$ rocket stove is a common design of a biomass stove that follows a set of basic principles, which results in more complete combustion and decreased fuel demand.
} 
cost interventions. When both approaches were combined, scenario ' $c$ ', there were more consistent health gains while simultaneously decreasing the cost of intervention compared to that of LPG or kerosene alone.

Bailis et al. (2005) also looked at cost-effectiveness, but compared both health and climate benefits of charcoal and fossil fuel stove interventions. They found both interventions have significant benefits for health compared to other biomass stoves, but the cost of fossil fuel stoves and the subsequent fuel required far exceeded that of a charcoal stove. Yet at the same time they also found charcoal stoves to have significant climate impacts, their 'charcoal-intensive' future projections predicted to increase GHG emissions 140-190\%.

In general cookstove interventions have been shown to be cost-effective investments due to the high amount of benefits that can result. Clean burning fossil fuel stoves have been shown in a number of studies to provide the highest amounts of 'win-win' benefits, but are also the most costly. Therefore the varying nuances of co-benefits for each intervention in addition to cost must be examined together.

\section{Tradeoffs in Actual Implementation}

Though both the cost-effective analyses and the cost-benefit analysis provide a strong argument for improved stove interventions based upon non-environmental benefits (e.g. either health or time savings), actually finding direct funding for these projects on this basis is limited. Carbon credits, on the other hand, provide a potential alternative source of funding that may be used to reach the world's poorest. The success of such projects will be dependent how the projects are designed (e.g. the type of stove, the cost of the stove vs revenue from carbon credits, strength of local partnerships, etc) and the extent to which projects integrate lessons learned from past cookstove 
intervention failures. These include, but are not limited to: accounting for user-preferences in stove design (Barnes et al. 1993, Rai and McDonald 2009), having a reliable supply chain established if switching to a different fuel (Rai and McDonald 2009, Wickramasinghe 2011), availability of replacement parts/stoves and maintenance resources (Rai and McDonald 2009), and user buy-in (Barnes et al. 1993, Rai and McDonald 2009, Shrimali et al. 2011). Additionally, outcomes of cookstove carbon credit projects will also largely be influenced by how success is defined (e.g. highest number of carbon credits generated or stoves distributed, women empowerment, or improving health) and by whom. If equity is of concern in such projects, then market approaches alone will not suffice to deliver improved cooking technology to the poorest of the poor (Simon et al. 2012).

Different implementing actors have different motivations for engaging in stove projects and this is inherently integrated in their implementation design (e.g. profit seeking market-based approaches) or indicated in their mandate (e.g. an environmental NGO vs poverty-alleviation NGO). Similarly they have different sources of funding, whether this is mostly donor, national, or investment funding which places limits on the scale of projects they can complete. These two factors combined with the target demographic of cookstove users in cookstove projects, greatly determine the financial capacity, scale, and design of such projects and the metrics used to measure success.

\section{Carbon Credits vs Health}

By design carbon credits automatically account for some of the global environmental benefits of cookstoves; the metric of value, tCO2e reduced translated into a carbon credit, directly calculating the amount of some of the GHGs reduced. Again, carbon credits only represent part of the total climate interactions. Additionally, both methodologies, CDM and GS, base these calculations on the amount of non-renewable biomass harvested that is reduced through use of the more efficient 
stove. Therefore areas with high rates of non-renewable harvest will result in the most carbon credits calculated. Though the methods for calculating this fraction involve significant uncertainty (Johnson et al. 2010; Simon et al. 2012), in theory using this fraction also integrates reduced pressures on local forest resources into the carbon credits. However, such projects do not base their benefits on any direct measurements on health or development outcomes and instead most cookstove carbon credit projects are just assumed to be 'win-win'.

A much different approach is needed if using health as a measure of success for cookstove interventions. Smith and Peel (2010) examined the dose-response curve for cardiovascular disease due to smoking and air pollution. They find there is a gap in available data about the health effects of inhalation of $\mathrm{PM}_{2.5}$ from approximately $10 \mathrm{mg} /$ day to $1 \mathrm{mg} /$ day intake, the levels at which inhalation of $\mathrm{PM}_{2.5}$ attributable towards the use of cookstoves fall. Though they express the need for more research to be done in this area, they extrapolate the number of deaths averted when switching from a) a heavy smoker to a light smoker, b) a light smoker to a village cook, c) a village cook to a passive smoker, and d) a passive smoker to a clean city. The most amount of deaths averted results from the last switch from a passive smoker to a clean city (1 to $0.1 \mathrm{mg} /$ day inhalation of $\mathrm{PM}_{2.5}$ ). The non-linearity in the dose-response curve indicates that improved stoves or modern fuels must result in significant reductions in emissions in order to maximize health benefits. In Grieshop et al. (2011)'s study the only stoves emitting less than $1 \mathrm{mg} /$ day of $\mathrm{PM}_{2.5}$ were the fossil fuel stoves, LPG and kerosene (See Table 1). Though Smith and Peel's study only examined the effects of cardiovascular disease, they expect a similar dose-response relationship for other diseases linked to intake of $\mathrm{PM}_{2.5}$, such as acute respiratory infections, pregnancy implications and cerebrovascular disease. Their one stated exception is lung cancer, which they predict would have more of a linear relationship. 
Even though theoretically based, this research has important implications for cookstove projects. Assuming the relationship projected by Smith and Peel (2010) is true, by far the best health intervention would be a fossil fuel stove, more specifically LPG. In the case of carbon credits, this would only be possible through a voluntary scheme as the CDM does not allow for fossil fuel stoves to qualify for carbon credits unless switching from a high to low-carbon intensive fossil fuel (e.g. coal to LPG). Additionally, as fossil fuels are on one of the upper rungs of the transition from traditional to modern fuels ${ }^{12}$ they are financially and physically available only to middle to upper income households living close enough to a town or city with an effective fuel supply chain.

Many areas outside of urban areas in developing countries lack a well-functioning supply chain to distribute fossil fuel stoves and fuel to rural communities. Therefore to maximize health in more rural settings would require significant efforts to establish a supply chain and also provide appropriate subsidies for such fuels to be affordable for households who currently cannot afford such technology. Under current circumstances, it seems access to these fuels will still only be provided for those with high enough incomes, as fuel subsidies can only go so far and often can result in unintended misallocation of benefits (Zerriffi 2011).

Carbon credits could help to offset some of these costs by providing an internal subsidy, but again earning carbon credits when switching to fossil fuels as the improved technology is only possible under the voluntary methodology in most scenarios, which currently earns less per credit than credits sold in the compliance market (Peters-Stanley and Hamilton 2012). Additionally the money earned through carbon credits under either methodology may not be enough to make such a venture profitable due to the relatively high cost of LPG. More technologically advanced improved

12 See Kowsari and Zerriffi (2011) for review of the household energy transition concept. 
biomass stoves such biomass gasifers or stoves with an integrated battery generated fan (e.g. Philip's 'fan' stove ${ }^{13}$ or Biolite's 'HomeStove'14), have higher rates of combustion than other more simply designed improved stoves and therefore emit less $\mathrm{PM}_{2.5}$. Due to their more complex technology they also cost more, but less than LPG, and could be a potential alternative to the LPG stove intervention while still providing increased health benefits relative to more basic models of improved stoves. The most cost effective improved cookstove with relatively high health benefits is the charcoal stove as discussed in Bailis et al. (2005), yet according to their projections, this would greatly increase GHG emissions.

\section{Representing Health in Carbon Credits?}

In Grieshop et al. (2011)'s analysis they included different GHGs and climate forcing species beyond those calculated in carbon credit markets. One climate-forcing species with a large GWP is black carbon. As previously mentioned black carbon is part of particulate matter emitted, which causes many of the health problems previously discussed. Including black carbon in carbon credit calculations has been proposed (PCIA 2011), but as of yet there has been no serious discussion of implementing this. Though there have not been any studies as of yet directly calculating the exact amount of carbon credits that could be produced when including black carbon, it would probably increase them due to its high GWP. The inclusion of black carbon may also help to inherently include health considerations in carbon credit calculations as this has direct implications for health

13 See: http://www.hedon.info/PhilipsWoodStove; http://www.research.philips.com/password/download/password_28.pdf ${ }^{14}$ See: http://biolitestove.com/homestove/overview/ 
unlike $\mathrm{CO}_{2}$ and $\mathrm{CH}_{4}$, the current GHGs included in such calculations. At the moment, this is just speculation and the actual impact of changing the methodologies is unknown.

\section{Summary}

Although improved cookstove projects can achieve 'win-win' benefits, as demonstrated in this paper, there are tradeoffs between the multiple benefits that can be produced.

If health is the priority, then one must seriously consider whether or not carbon credits are the best mechanism to implement a cookstove project. Carbon credits limit the location in which such projects can be implemented to only those with fuel being harvested at non-renewable rates, but at the same time provide an opportunity to fund projects that have the potential to have financial sustainability while targeting some of the world's poorest population. For climate, carbon credits already help to support these objectives.

If 'win-win' benefits are an explicit goal of the project, then they need to be concretely defined. They should clearly delineate objectives and indicate how success is to be measured in order to design an appropriate cookstove project that can achieve high levels of multiple benefits.

\section{Conclusion}

When implementing cookstove projects, different models of improved cookstoves present tradeoffs between the levels of climate and health benefits that can be achieved. Therefore achieving 'winwin' benefits in such projects can also involve a tradeoff of benefits. When implementing cookstove projects, details such as type of stove, target demographic, and location will all impact the outcome of such projects and the amount of different benefits generated. 
Without a conscious effort to balance the different benefits that can be generated, carbon credits will tend to prioritize climate over health benefits. Tools such as the sustainable development matrix requirements under the GS framework are good, but are not considered enough to ensure sustainable development in such projects. This does not mean that the use of carbon credits should be abandoned. Such financial opportunity can enable large-scale cookstove diffusion and target some of the world's poorest populations while improving prospects for financial sustainability. It does raise the question, however, of how other benefits can be incorporated into the crediting framework to ensure proper balance between different objectives.

One possibility is the inclusion of black carbon in carbon credit calculations. This has the potential to incorporate some level of health benefits directly into calculations, but actual implications of this are unknown. Objectives and definition of success of any cookstove project need to be explicitly and concretely defined at the beginning of the project, as these definitions will have great impact on project design and the resulting benefits created. If health is the priority and project funds are available, carbon credits may not always be the best method for implementing such a project.

\section{Acknowledgements}

The authors appreciate the insight and guidance from Dr. Andrew Grieshop (Dept. of Civil, Construction, and Environmental Engineering, North Carolina State University) who provided quintessential support. Additionally they would like to thank the organizers and participants of the Future Forestry Leaders Symposium for fostering a stimulating, intellectual environment to share and extend graduate students' research. Funding was provided through Natural Sciences and Engineering Research Council of Canada and the Bridge Canadian Institutes of Health Research Strategic Training Fellowship. 


\section{References}

Bailis, R., M. Ezzati and D. M. Kammen. 2005. Mortality and Greenhouse Gas Impacts of Biomass and Petroleum Energy Futures in Africa. Science 308:98-103.

Bailis, R., A. Cowan, V. Berrueta and O. Masera. 2009. Arresting the Killer in the Kitchen: The Promises and Pitfalls of Commercializing Improved Cookstoves. World Development 37:16941705.

Barnes, D.F., K. Openshaw , K. R. Smith and R. van der Plas. 1993. The design and diffusion of improved cooking stoves. The World Bank Research Observer 8:119-141.

Blunck, M., C. Griebenow, M. Rammelt and C. Zimm. 2011. Carbon Markets for Improved Cooking Stoves., A GIZ guide for project operators. GIZ-HERA - Poverty-oriented Basic Energy Services:1-63.

Bond T, C. Venkataraman and 0. Masera. 2004. Global atmospheric impacts of residential fuels. Energy for Sustainable Development 8:20-32.

Bruce, N, R. Perez-Padilla and R Albalak. 2000. Indoor air pollution in developing countries: a major environmental and public health challenge. Bull. World Health Organ. 78:1078-1092.

Bumpus, A. G. 2009. The geographies of carbon offsets: governance, materialities and development. University of Oxford, Oxford, U.K. p. 1-365.

Bumpus, A.G. and J.C. Cole. 2010. How can the current CDM deliver sustainable development? WIREs Climate Change 1:541-547.

Bumpus, A.G. 2011. The Matter of Carbon: Understanding the Materiality of tCO2e in Carbon Offsets. Antipode 43:612-638.

Chaurey, A., P.R. Krithika, D. Palit, S. Rakesh and B.K. Sovacool. 2012. New partnerships and business models for facilitating energy access. Energy Policy [In Press] :1-8.

Cosbey, A., J. Parry, J. Browne, Y. D. Babu, P. Bhandari, J. Drexhage and D. Murphy. 2005. Realizing the Development Dividend: Making the CDM Work for Developing Countries (Phase I 
Report). International Institute for Sustainable Development [Internet]:1-72. (Available from: http://www.iisd.org/climate/global/dividend.asp).

Cox, P. 2011. Analysis of Cookstove Change-Out Projects Seeking Carbon Credits. University of Minnesota Law School [Internet]:1-51. (Available from:

http://papers.ssrn.com/sol3/papers.cfm?abstract_id=1839765).

Elias, R.J. and D.G. Victor. 2005. Energy transitions in developing countries: a review of concepts and literature. The Program on Energy and Sustainable Development, Standford University [Working Paper\# 40]: 1-33.

Food and Agriculture Organization (FA0). 2002. Chapter 2: Wood As An Energy Source. In Economic Analysis of Wood Energy Systems. FAO. (Available from: http://www.fao.org/DOCREP/006/Y4327E/Y4327E00.HTM).

Figueres ,C. 2006. Sectoral CDM: Opening the CDM to the yet Unrealized Goal of Sustainable Development. International Journal of Sustainable Development, Law \& Policy 2:1-20.

Global Alliance for Clean Cookstoves (GACC). 2011. Working Group Early Action Items. GACC [Internet]:1-47. (Available from: http://cleancookstoves.org/wp-content/uploads/2011/06/EarlyAction-Item-Compilation-FINAL.pdf).

Grieshop A.P., C.C.O. Reynolds CCO, M. Kandlikar and H. Dowlatabadi. 2009. A black-carbon mitigation wedge. Nature Publishing Group 2:533-534.

Grieshop, A.P., J. D. Marshall and M. Kandlikar. 2011. Health and climate benefits of cookstove replacement options. Energy Policy 39:7530-7542.

Hanbar, R.D. and P. Karve. 2002. National Programme on Improved Chulha (NPIC) of the Government of India: an overview. Energy for Sustainable Development 6:49-55.

Holdren, J.P. and K. R. Smith. 2000. Chapter 3: Energy, the Environment, and Health. In Energy and the challenge of sustainability. United Nations Development Programme, New York: 61-104. Hutton, G., E. Rehfuess, F. Tediosi and S. Weiss. 2006. Evaluation of the costs and benefits of 
household energy and health interventions at global and regional levels Summary. World Health Organization [Internet]:1-19. (Available from:

http://www.who.int/indoorair/publications/summary/en/index.html).

Jetter, J.J., and P. Kariher. 2009. Solid-fuel household cook stoves: Characterization of performance and emissions. Biomass and Bioenergy 33:294-305.

Johnson, M., R. Edwards and 0. Masera. 2010. Improved stove programs need robust methods to estimate carbon offsets. Climatic Change 102:641-649.

Kowsari, R. and H. Zerriffi. 2011. Three dimensional energy profile A conceptual framework for assessing household energy use. Energy Policy 39:7505-7517.

Legros, G., I. Havet , N. Bruce and S. Bonjour. 2009. The energy access situation in developing countries: a review focusing on the least developed countries and Sub-Saharan Africa. United Nations Development Programme and the World Health Organization[Internet]: 1-130. (Available from: http://www.who.int/indoorair/publications/energyaccesssituation/en/index.html).

Matinga, M.N. 2008. The making of hardiness in women's experience of health impacts of wood collection and use in Cuntwini, rural South Africa. Medische Anthropologie 20: 279-295.

Mehta, S. and C. Shahpar. 2004. The health benefits of interventions to reduce indoor air pollution from solid fuel use: a cost-effectiveness analysis. Energy for Sustainable Development 8:1-7.

Naeher, L.P., M. Brauer, M. Lipsett, J.T. Zelikoff, C.D. Simpson, J.Q. Koenig and K. R. Smith. 2007. Woodsmoke Health Effects: A Review. Inhalation Toxicology 19:67-106.

Olsen, K.H. 2007. The clean development mechanism's contribution to sustainable development: a review of the literature. Climatic Change 84:59-73.

Parikh, J. 2011. Hardships and health impacts on women due to traditional cooking fuels A case study of Himachal Pradesh, India. Energy Policy 39:7587-7594.

Patrick, E. 2007. Sexual violence and firewood collection in Darfur. Forced Migration Review $27: 40-41$. 
Partnership for Clean Indoor Air (PCIA). 2011. Perspectives: Allocating Carbon Revenue.

Webinar, 15 Dec 2011. PCIA [Internet] (Available from:

http://www.pciaonline.org/Webinar_Perspectives_Allocating_Carbon_Revenue).

Pearson, B. 2006. Market failure: why the Clean Development Mechanism won't promote clean development. Journal of Cleaner Production 15:247-252.

Peters-Stanley, M. and K. Hamilton. 2012. Developing Dimension: State of the Voluntary Carbon Markets 2012. Ecosystem Marketplace \& Bloomberg New Energy Finance :1-90.

Pine, K., R. Edwards, O. Masera, A. Schilmann, A. Marrón-Mares and H. Riojas-Rodríguez

2011. Adoption and use of improved biomass stoves in Rural Mexico. Energy for Sustainable Development 15:176-183.

Pope, D.P., V. Mishra, L. Thompson, A.R. Siddiqui , E.A. Rehfuess, M. Weber and N.G. Bruce.

2010. Risk of Low Birth Weight and Stillbirth Associated With Indoor Air Pollution From Solid Fuel Use in Developing Countries. Epidemiologic Reviews 32:70-81.

Rai, K. and J. McDonald. 2009. Cookstoves and Markets: Experiences, Successes and Opportunities. GVEP International :1-41.

Rehfuess, E. 2006. Fuel for life: household energy and health. World Health Organization [Internet]:1-42. (Available from:

http://www.who.int/indoorair/publications/fuelforlife/en/index.html).

Roden, C.A., T.C. Bond, S. Conway and A.B.o. Pinel 2006. Emission Factors and Real-Time Optical Properties of Particles Emitted from Traditional Wood Burning Cookstoves. Environ. Sci. Technol. 40:6750-6757.

Ruiz-Mercado, I., O. Masera, H. Zamora and K.R. Smith. 2011. Adoption and sustained use of improved cookstoves. Energy Policy 39:7557-7566.

Shrimali, G., X. Slaski, M.C. Thurber and H. Zerriffi. 2011. Improved stoves in India: A study of sustainable business models. Energy Policy 39:7543-7556.

Simon, G.L., A.G. Bumpus and P. Mann. 2012. Win-win scenarios at the climate-development 
interface: Challenges and opportunities for stove replacement programs through carbon finance. Global Environmental Change 22:275-287.

Sinton, J.E., K.R. Smith, J.W. Peabody, L. Yaping, Z. Xiliang, R. Edwards and G. Quan. 2004. An assessment of programs to promote improved household stoves in China. Energy for Sustainable Development 8:33-52.

Smith, K.R., G. Shuhua, H. Kun, Q. Daxiong. 1993. One hundred million improved cookstoves in China: how was it done? World Development 21:941-961.

Smith, K.R., J.M. Samet, I. Romieu and N. Bruce. 2000a. Indoor air pollution in developing countries and acute lower respiratory infections in children. Thorax 55:518-532.

Smith, K.R., R. Uma, V. Kishore, J. Zhang, V. Joshi and M. Khalil. 2000b. Greenhouse implications of household stoves: an analysis for India. Annu. Rev. Energy Environ. 25:741-763.

Smith, K.R. and S. Mehta. 2003. The burden of disease from indoor air pollution in developing countries: comparison of estimates. Int J Hyg Environ Health 206:279-289.

Smith, K.R. and E. Haigler. 2008. Co-Benefits of Climate Mitigation and Health Protection in Energy Systems: Scoping Methods. Annu. Rev. Public. Health. 29:11-25.

Smith, K.R., M. Jerrett, H.R. Anderson, R.T. Burnett, V. Stone, R. Derwent, R.W. Atkinson, A. Cohen, S.B. Shonkoff, D. Krewski, C.A. Pope III, M.J. Thun and G. Thurston. 2009a. Public health benefits of strategies to reduce greenhouse-gas emissions: health implications of short-lived greenhouse pollutants. The Lancet 374:2091-2103.

Smith, K.R., J.P. Mccracken, L. Thompson, R. Edwards, K.N. Shields, E. Canuz and N. Bruce. 2009b. Personal child and mother carbon monoxide exposures and kitchen levels: Methods and results from a randomized trial of woodfired chimney cookstoves in Guatemala (RESPIRE). Journal of Exposure Science and Environmental Epidemiology 1-11.

Smith, K.R. and J.L. Peel. 2010. Mind the Gap. Environ Health Perspect 118:1643-1645. 
Smith, K.R. and K. Dutta. 2011. “Cooking with Gas”. Energy for Sustainable Development 15(2):115-116.

Sterk, W. and B. Wittneben. 2006. Enhancing the clean development mechanism through sectoral approaches: definitions, applications and ways forward. Int Environ Agreements 6:271-287.

The Gold Standard (GS). 2012. Validating carbon reductions and community development: GS Methodologies. The Gold Standard [Internet] (Available from:

http://www.cdmgoldstandard.org/project-certification/gs-methodologies] [Accessed 24 April 2012].

The Gold Standard (GS). 2011. What we do. The Gold Standard [Internet] (Available from: http://www.cdmgoldstandard.org/What-we-do.64.0.html) [Accessed 08 August 2011].

Top, N., N. Mizoue, S. Ito and S. Kai. 2004. Spatial analysis of woodfuel supply and demand in Kampong Thom Province, Cambodia. Forest Ecology and Management 194:369-378.

Troncoso, K., A. Castillo, L. Merino, E. Lazos and O.R. Masera. 2011. Understanding an improved cookstove program in rural Mexico An analysis from the implementers' perspective. Energy Policy 39:7600-7608.

United Nations (UN). 1998. Kyoto Protocol to the United Nationals framework convention on climate change. UNFCC, United Nations :1-21.

United Nations Framework Convention on Climate Change (UNFCCC). 2011. About CDM. UNFCCC [Internet] (Available from: http://cdm.unfccc.int/about/index.html) [Accessed 08 August 2011].

World Health Organization (WHO). 2004. The global burden of disease, 2004 update. World Health Organization:1-146.

Wickramasinghe, A. 2003. Gender and health issues in the biomass energy cycle: impediments to sustainable development. Energy for Sustainable Development 7(3): 51-61. 
Wickramasinghe, A. 2011. Energy access and transition to cleaner cooking fuels and technologies in Sri Lanka Issues and policy limitations. Energy Policy 39:7567-7574.

Wilkinson, P., K.R. Smith, M. Davies, H. Adair, B.G. Armstrong, M. Barrett, N. Bruce, A. Haines, I. Hamilton, T. Oreszczyn, I. Ridley, C. Tonne and Z. Chalabi. 2009. Public health benefits of strategies to reduce greenhouse-gas emissions: household energy. The Lancet 374:1917-1929. Zerriffi, H. 2011. Innovative business models for the scale-up of energy access efforts for the poorest. Current Opinion in Environmental Sustainability 3:272-278.

Zhang, J., K.R. Smith, Y. Ma, S. Ye, F. Jiang, W. Qi, P. Liu, M. Khalil, R. Rasmussen and S. Thorneloe. 2000. Greenhouse gases and other airborne pollutants from household stoves in China: a database for emission factors. Atmospheric Environment 34:4537-4549.

Zhou, Z., K. L. Dionisio, R. E. Arku, A. Quaye, A. F. Hughes, J. Vallarino, J.D. Spengler, A. Hill, S. Agyei-Mensah and M. Ezzati. 2011. Household and community poverty, biomass use, and air pollution in Accra, Ghana. PNAs 108(27): 11028-11033. 